and in reply he explained that it was not possible to estimate "the cost of Geological Surveys and the time necessary for their completion, as until some examination of a given area has been effected no correct idea of the whole expenditure can be formed". The region then under consideration was South Wales, and, he continued, "The coal and iron districts require great care both in scientific and economic points of view, and hence far more time has to be bestowed upon them, than upon most other portions of the country . . . but perhaps thrown in with South Wales generally the whole may be taken at about $£ 1$ per square mile".

Colby also replied to the Board, pointing out that the letter which he had received "contains no reply whatever to the original question of $\mathrm{Mr}$. De la Beche being permitted to hire assistants", and stating that he (Colby) had realized the necessity for hiring assistants during the progress of the work in Devonshire.

Careful handling of the situation eventually resulted in an official acknowledgment that it was not possible to foresee and to legislate for every contingency that was likely to arise during the course of a geological survey, and on March 15 it was reported that, "The Master General and Board consider the explanation given to be so far satisfactory as that it limits his labours to the completion of certain parts of the Survey for which the authority of the Treasury has been obtained, and to this he must be confined until the Master General and Board receive further instructions on the subject. With respect to the expenditure, the only plan . . . will be, from year to year, to take such a sum as may be deemed advisable, upon which point the Master General and Board would from time to time avail themselves of your opinion and so check any extraordinary expense that may be proposed".

De la Beche was quick to act upon the recommendation, for in April he wrote, in a letter to Colby : "I have picked up one very clever hand as an assistant at $7 \mathrm{~s}$. per day, a regular good one he is, and I am now on the look out for others". The "regular good one" was David Hiram Williams, who after rendering useful service in South Wales joined the Indian Survey, and his name was given in the "Return of Geological Assistants employed on the Geological Survey of England and Wales", which de la Beche made in June 1839. It will be noted that he wrote of the "Survey of England and Wales", although at the time he had only had authority to work in South Wales.

The "Return" for September 1839 contained two names, for Josiah Rees had been appointed at a salary of five shillings a day, and in December, when de la Beche submitted his estimates for the coming year, he budgeted for four assistants and a total expenditure of $£ 1,400$, while in the following year he budgeted for six, and a total expenditure of $£ 1,900$ -but the question of the possible limit to the duration of the Survey was not raised again, and before the work in South Wales was completed de la Beche was seeking permission to extend his operations into the Forest of Dean!

\title{
Hydrogenation of Oils by the Continuous Process
}

$\mathrm{V}$ T. Athavale and S. K. K. Jatkar have recently carried out a detailed study of hydrogenation of ethyl oleate using nickel-carbonate kieselguhr catalyst ( $J$. Indian Inst. Sci., 21, A, Part 25, 1938) and show a definite advance on previously recorded results. Iodine values, refractive indices and dispersions were determined on a number of samples of hydrogenated ethyl oleate, and results are recorded graphically. Contrary to expectation, iodine values did not vary linearly with refractive index in the initial stages of hydrogenation, but only after the iodine value had fallen by about twenty-five per cent. Comparison of refractive index and dispersion values of samples hydrogenated at different temperatures and with different rates of flow of ethyl oleate over the catalyst showed that dispersions of samples having almost identical refractive indices vary considerably. Similarly, it was found that samples having the same iodine value had dissimilar dispersions, thus indicating the formation of oleic acid during the reaction. A study of the effect of temperature on the velocity of hydrogenation at a fixed rate of flow of ethyl oleate over the catalyst further revealed a marked difference in dispersion values of samples hydrogenated at low temperatures and the conclusion was, therefore, reached that the isomers of oleic acid are formed because of the low activity for hydrogenation of the catalyst at low temperatures.

Interconnected with this research a further series of experiments were undertaken by the same authors (J. Indian Inst. Sci., 21, A, Part 26, 1938). Earlier work had pointed to the possibility that variations in velocity coefficients of hydrogenation of oils might be due not only to differences in composition of the oils, but equally to differences in the heterogeneity of the catalyst surface. Consequently, a study was undertaken of the velocity coefficients for the hydrogenation of ground-nut oil in the presence of nickelcarbonate-kieselguhr, unsupported nickel-carbonate, nickel-hydroxide-silica gel and nickel-peroxide-kieselguhr catalysts. A comparison was then made with the velocity coefficients of hydrogenation of the same oil over a nickel-wire catalyst. Velocity coefficients $(K)$ were calculated from the equation:

$$
K=\frac{2 \cdot 3}{t} \log \frac{a}{(a-x)} ;
$$

where $x$ is the percentage conversion at a given rate and $t$ is the time of contact. This velocity coefficient was further corrected for the effect of absorption

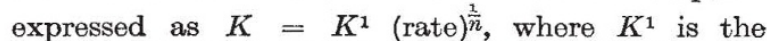
corrected velocity coefficient. By plotting the value $K^{1}$ for different samples of oil against temperature, curves showing a maximum at $150^{\circ}$ were obtained. This appeared to depend upon the percentage of olein in the oil and its selective hydrogenation at that temperature. 